\title{
Erectile Dysfunction in Hemodialysis in Togo
}

\section{Kossi Akomola Sabi' ${ }^{1}$, Béfa Noto Kadou Kaza ${ }^{*}$, Eyram Yoan Amekoudi' ${ }^{1}$ Jacques Vigan², Souleymane Pessinaba ${ }^{3}$, Kafui Avouwadan'1, Kodjo Tengue ${ }^{4}$, Tchilabalo Matchona Kpatcha ${ }^{4}$, Dazé Apollinaire Gnionsahe ${ }^{5}$}

${ }^{1}$ Departement of Nephrology and Hemodialysis, Sylvanus Olympio University Teaching Hospital, Lomé, Togo

${ }^{2}$ Departement of Nephrology and Hemodialysis, University Teaching Hospital of Cotonou, Cotonou, Benin

${ }^{3}$ Departement of Cardiology, Campus University Teaching Hospital of Lomé, Lomé, Togo

${ }^{4}$ Departement of Urology and Andrology, Sylvanus Olympio University Teaching Hospital, Lomé, Togo

${ }^{5}$ Departement of Nephrology and Hemodialysis, University Teaching Hospital of Yopougon, Abidjan, Ivoiry Coast

Email: kossi.sabi@gmail.com, ×bfanotokadoukaza@yahoo.fr, eyramyoan@gamil.com, viques2@yahoo.fr

How to cite this paper: Sabi, K.A., Kaza, B.N.K., Amekoudi, E.Y., Vigan, J., Pessinaba, S., Avouwadan, K., Tengue, K., Kpatcha, T.M. and Gnionsahe, D.A. (2016) Erectile Dysfunction in Hemodialysis in Togo. Open Journal of Nephrology, 6, 145-150. http://dx.doi.org/10.4236/ojneph.2016.64018

Received: October 21, 2016

Accepted: December 16, 2016

Published: December 19, 2016

Copyright $\odot 2016$ by authors and Scientific Research Publishing Inc. This work is licensed under the Creative Commons Attribution International License (CC BY 4.0).

http://creativecommons.org/licenses/by/4.0/ (c) (i) Open Access

\section{Abstract}

Objectives: To determine the prevalence and risk factors of erectile dysfunction (ED) in men on hemodialysis in Togo. Methods: Prospective cross-sectional study, descriptive and analytical ranging from December 2015 to February 2016 in the hemodialysis unit of CHU SO, only dialysis center in the country. The evaluation of the ED was made through IIEF-5 questionnaire. Results: 39 men (67.2\%) of 58 hemodialysis is a sex ratio $\mathrm{M} / \mathrm{F}$ of 2.05 . The average age was 43.5 years with extremes of 25 and 59 years. The majority of men had a profession in 19 cases (48.7\%). The mean duration of dialysis was 30 months with a range of 4 months and 90 months. Initial glomerular nephropathy was in 19 cases (48.7\%) and vascular in 14 cases (35.9\%). 38 patients were hypertensive (97.4\%) and 6 diabetic men (15.4\%). The prevalence of ED was $74.3 \%$ (29 cases). ED score was less than 10 points in 14 cases (35.9\%); 01 case (2.6\%) between 11 and 16 points; 06 cases (15.4\%) between 17 to 21 points; 08 cases (20.5\%) between 22 and 25 points; and 10 cases (25.6\%) between 26 and 30 points. Age, profession and duration of dialysis were risk factors associated with ED $(\mathrm{P}<$ 0.001). Conclusion: The prevalence of ED is very high in Togo.

\section{Keywords}

Erectile Dysfunction, Hemodialysis, Togo

\section{Introduction}

According to the American society of psychiatrics, erectile dysfunction is determined by the persistent inability for a man to have or to maintain an adequate erection till the 
end of a sexual intercourse. This is as a result of a difficulty or an interpersonal difficulty [1]. Many studies have been carried throughout the world on erectile dysfunction in the USA [2], in Italy [3] [4] and in France [5] [6] [7]. It occurs more and more in the general population but is pronounced in some individuals like those with chronic kidney diseases [7]. In France, Kleinclausss et al. [7] estimated erectile dysfunction to be between $50 \%$ and $70 \%$ depending on the stage of chronic kidney failure. In sub-Saharan Africa, few studies have been carried out; in Mali, Diallo et al. [8] found a 76.7\% reduction in sexual activity amongst patients on hemodialysis. In Togo, there is no study yet or data on erectile dysfunction in the general population and particularly on men who are undergoing hemodialysis. This prompted us to carry out this study with the main objective of determining the prevalence of erectile dysfunction in men on hemodialysis in Togo and to identify its risk factors.

\section{Methodology}

It was a transverse, prospective, descriptive and analytical study that ran from December 2015 to February 2016 in the hemodialysis unit of CHU SYLVANUS OLYMPIO the solitary center in the country. Were included in this study all men with chronic renal failure on periodic hemodialysis for more than a month and who accepted to complete our questionnaire. Our general data was collected using a personalized investigation form for each patient on hemodialysis. Sexual function was evaluated using the French version 5 of the International Index for Erectile Dysfunction (IIED) [9]. The IIED-5 is composed of 04 questions from the IIED on erectile function (Q2, 4, 5 and 15) and 01 question on sexual satisfaction (Q7). Each answer to a question is regrouped and graded between 0 and 5 . The total score on the answers lead to the determination of erectile dysfunction in 5 categories: absence of erectile dysfunction for a score between 26 and 30, mild for a score between 22 and 25, mild to moderate for a score between 17 to 21 , moderate between 11 and 16 and sever erectile dysfunction for a score between 6 and 10. Data was analyzed using Epi info version 2002. Both descriptive and inferential statistics were used. Descriptive statistics used in the study were frequencies, percentage, mean median, range, and standard deviation. Chi-square, two-sample and paired $\mathrm{t}$-tests, the Mann Whitney test, for inferential statistics as deemed appropriate; $\mathrm{p}$ $<0.05$ was considered as significant.

\section{Results}

During our period of study, among 58 patients on hemodialysis in our center, 39 were males (67.2\%) with a sex ratio of M/F 2.05. The average age was 43.5 years with extremes being 25 and 57. Distribution with respect to age showed 5 cases (12.8\%) between 26 and 35 years, 11 cases (28.2\%) between 36 and 45 years 13 cases (13.3\%) between 46 and 55 years, 9 cases (23.1\%) between 56 and 65 years and 01 case $(2.6 \%)>65$ years. A majority of men 19 cases (48.7\%) were of a liberal profession followed by civil servants 17 cases $(23.6 \%)$ and 3 cases $(7.7 \%)$ were unemployed. The average duration on dialysis was 30 months with extremes of 4 months and 90 months. The duration on 
dialysis was $<1$ year in 9 cases (23.1\%) between 1 and 5 years in 21 cases (52.8\%) and above 05 years in 9 cases $(23.1 \%)$. The route of dialysis was arteriovenous fistula in 29 cases $(74.4 \%)$ and a central venous catheter in 10 cases (25.6\%). Initial nephropathy was found to be from the glomerulus in 2 cases $(5.1 \%)$ and was undetermined in 4 cases (10.3\%). Thirty eight men were hypertensive (997\%) and 6 were diabetic and hypertensive (15.4\%). Diuretics and calcium channel blockers were used for the treatment of the thirty eight hypertensive patients. The prevalence of erectile dysfunction was $74.3 \%$ (29 cases). The erectile dysfunction score was found to be less than 10 points in 14 cases (35.9\%); 01 case (2.6\%) between 11 and 16 points; 06 cases (15.4\%) between 17 and 21 points; 08 cases (20.5\%) between 22 and 25 points; and 10 cases (25.6\%) between 26 and 30 points. Age, duration on dialysis and profession were significantly associated with risk of developing erectile dysfunction with $\mathrm{P}<0.001$ (Table 1).

Table 1. Factors associated with ED.

\begin{tabular}{|c|c|c|c|}
\hline & $\mathrm{ED}(+)[\mathrm{n}=29(74.3 \%)]$ & $\operatorname{ED}(-)[n=10(25.7 \%)]$ & $\mathrm{P}$ \\
\hline AGE & & & $<0.001$ \\
\hline $26-35$ & $4(13.8)$ & $1(10)$ & \\
\hline $36-45$ & $9(31)$ & $2(20)$ & \\
\hline $46-55$ & $7(24.1)$ & $6(60)$ & \\
\hline $56-65$ & $8(27.7)$ & $1(10)$ & \\
\hline$>65$ & $1(3.4)$ & & \\
\hline PROFESSION & & & $<0.001$ \\
\hline Unemployed & $2(6.8)$ & $1(10)$ & \\
\hline Liberal & $16(55.3)$ & $3(30)$ & \\
\hline State civil servant & $7(24.1)$ & $3(30)$ & \\
\hline Private civil servant & $4(13.8)$ & $3(30)$ & \\
\hline DURATION OF DIALYSE & & & $<0.001$ \\
\hline$<1$ year & $7(24.1)$ & $2(20)$ & \\
\hline $1-5$ years & $14(48.3)$ & $7(70)$ & \\
\hline$>5$ years & $8(27.6)$ & $1(10)$ & \\
\hline ROUTE & & & 0.25 \\
\hline $\mathrm{AVF}$ & $21(72.4)$ & $8(80)$ & \\
\hline Central venous catheter & $8(27.6)$ & $2(20)$ & \\
\hline \multicolumn{4}{|l|}{ Comorbidity } \\
\hline HBP & $21(72.5)$ & $8(80)$ & 0.19 \\
\hline HBP + Diabetes & $4(13.8)$ & $2(20)$ & 0.46 \\
\hline HBP + sickle cell & $1(3.4)$ & & \\
\hline $\mathrm{HBP}+$ prostate cancer & $2(6.9)$ & & \\
\hline Asthma & $1(3.4)$ & & \\
\hline
\end{tabular}




\section{Discussion}

Our study was carried out in the hemodialysis center of CHU SYLVANUS OLYMPIO Togo the only dialysis center in the country. The limit of this study is the methodology used to evaluate sexual function. If the IIED questionnaire is accepted and valid, hormonal and biological factors were not considered in this study. The sample size 39 men could limit the interpretation of results. Socio cultural African tradition prevented patients from talking freely about their sexual life. Although this bias, this study is the first of its kind in TOGO and has permitted the determination of the prevalence and associated factors of erectile dysfunction in patients on hemodialysis. The average age of outpatients was 43.5 years, similar investigations of Bouattar et al. [10] and Diallo et al. [8]. This is explained by the fact that sexual disorders are found in sexually active population. Just like with Messina et al. [11] who found 95.8\% high blood pressure in their series and $24.9 \%$ of diabetics we registered 38 cases of high blood pressure (97.4\%) 06 cases (15.4\%) who were followed up for high blood pressure and diabetes. The high percentage of high blood pressure and diabetes can be explained by the fact that they are responsible for arteriosclerosis, which has a relationship with sexual disorder in chronic kidney failure. The prevalence of erectile dysfunction in our series was $74.3 \%$ with $35.9 \%$ being severe. The result is like that got by Avakoudjo et al. [12] in Benin, $75.9 \%$ of erectile dysfunction with $29.3 \%$ being severe erectile dysfunction. Arteriosclerosis is accelerated by chronic kidney failure and may explain the increase rate of erectile dysfunction in patients on hemodialysis. The high rate of high blood pressure and diabetes confirms this in our series. The high rate might even be an underestimation in our African society where socio economic context prevents patients from talking about sexuality freely. For Bouattar et al. [10] in Morocco, the prevalence of erectile dysfunction was $84 \%$ with $8 \%$ cases of severe erectile dysfunction before kidney transplant. The relatively low rate of severe erectile dysfunction in Morocco may be explained by the better management of patients in the North of the Sahara. The relationship between age and erectile dysfunction was statistically significant $(\mathrm{P}<0.001)$. The result is identical to that of Costa et al. in France [13] whose prevalence gave a correlation between erectile dysfunction and age: between 40 to 70 years, the relative risk of erectile dysfunction is multiplied by 2 to 4 . Feldman [2] reported the same thing in his study where the age appeared to be the most independent of all the risk factors. They noticed that between the age 40 and 70 years, the risk of severe erectile dysfunction and moderate erectile dysfunction was $5 \%$ to $15 \%$ and of $17 \%$ to $34 \%$ respectively. The fact that occupation appears associated with erectile dysfunction $(\mathrm{P}>0.001)$, can be explained by the bias of selection related to the high cost of dialysis in Togo ( 0.97 times minimum wedge per session). This explains why 19 cases (48.7\%) of patients on hemodialysis were of the liberal profession and civil servants 17 case (23.6\%). The relationship between erectile dysfunction and duration of dialysis is statistically significant $(\mathrm{P}<0.001)$. Droupy [14] et al. Kleinclauss [7] equally mentioned amongst the risk factors the time or duration that a patient has been on dialysis. One of the explication could be a continuous and progressive worsening of arteriosclerosis. This hypothesis is confirmed by the results 
got in patients who undergo kidney transplant at an early stage of chronic kidney failure that seems to ameliorate their erectile dysfunction. The sessions of dialysis could also be a cause like in the series of Avakoudjo et al in Benin [12] where 39 patients (67.2\%) accepted having erectile dysfunction during dialysis. Even if many studies have demonstrated a past history of cadio vascular disease, high blood pressure, diabetes or dyslipidemia were risk factors for erectile dysfunction in chronic kidney failure [2] [7] [12], these risk factors for arteriosclerosis seem not to have any effect on erectile dysfunction in our series Krishnan et al. [15].

\section{Conclusion}

The prevalence of erectile dysfunction in men on hemodialysis is very high in Togo and the associated factors are: age, profession, and duration of dialysis. Our study is the first of its kind in Togo, it should be considered as a basis for other studies. It has to be confirmed by other studies that will take hormonal levels into consideration.

\section{References}

[1] American Psychiatric Association (2003) DSM-IV-TR Diagnostic and Statistical Manual of Mental Disorders. 4th Edition, Masson, Paris, 629-631.

[2] Feldman, H.A., Goldstein, I., Hatzichristou, D.G., et al. (1994) Impotence and Its Medical and Psychosocial Correlates: Results of the Massachusetts Male Aging Study. The Journal of Urology, 151, 54-61.

[3] Fedele, D., Coscelli, C., Santeusanio, F. et al. (1998) Erectile Dysfunction in Diabetic Subjects in Italy. Diabetes Care, 21, 1973-1977. https://doi.org/10.2337/diacare.21.11.1973

[4] Antonucci, M., Palermo, G., Recupero, S.M., Bientinesi, R., Presicce, F., Foschi, N., Bassi, P. and Gulino, G. (2016) Male Sexual Dysfunction in Patients with Chronic End-Stage Renal Insufficiency and in Renal Transplant Recipients. Italian Archive of Urology and Andrology, 87, 299-305. https://doi.org/10.4081/aiua.2015.4.299

[5] Giuliano, F., Leriche, A., Jaudinot, E.O., et al. (2004) Prevalence of Erectile Dysfunction among 7689 Patients with Diabetes or Hypertension, or Both. Urology, 64, 1196-1201. https://doi.org/10.1016/j.urology.2004.08.059

[6] Delavierre, D. (2002) Epidemiology of Erectile Dysfunction: Risk Factors. Andrologie, 12, 323-331. https://doi.org/10.1007/BF03034649

[7] Kleinclauss, F., Kleinclauss, C. and Bittard, H. (2005) Erectile Dysfunction in Patients with Renal Impairment and Renal Transplant. Progrès en urologie, 15, 447-456.

[8] Diallo, D., Fongoro, S., Doumbia, S., et al. (2011) Study of the Quality of Life for Hemodialysis Patients at the University Hospital of Point G in Bamako: About 30 Cases. Mali Medical, 26, 16-20.

[9] Arslan, D., Aslan, G., Sifil, A., et al. (2002) Sexual Dysfunction in Male Patients on Hemodialysis: Assessment the International Index of Erectil Function (IIEF). International Journal of Impotence Research, 14, 539-542. https://doi.org/10.1038/sj.ijir.3900937

[10] Bouattar, T., Benamar, L., Ouzeddoun, N., et al. (2009) Erectile Dysfunction in Kidney Transplant. Morocco Journal of Urology, 15, 11-14.

[11] Pereira Mesquita, J.F., Ramos, T.R., Pereira Mesquita, F., et al. (2012) Prevalence of Erectile Dysfunction in Chronic Renal Disease Patients on Conservative Treatments. Clinics, 67, 181-183. https://doi.org/10.6061/clinics/2012(02)15 
[12] Avakoudjo, J., Pare, A., Vigan, J., et al. (2012) Erectile Dysfunction in Patients Undergoing Hemodialysis in CNHU-HKM Cotonou: Epidemiological Profile. Andrologie, 22, 246-251.

[13] Costa, P., Grivel, T., Guiliano, F., et al. (2005) Erectile Dysfunction: A Sentinel Symptom. Progrès en urologie, 15, 203-207.

[14] Droupy, S. (2005) Epidemiology and Physiology of Erectile Dysfunction. Annales d urologie, 39, 71-84. https://doi.org/10.1016/j.anuro.2005.04.004

[15] Krishnan, R., Izatt, S., Bargman, J.M., et al. (2003) Prevalence and Determinants of Erectile Dysfunction in Patients on Peritoneal Dialysis. International Urology and Nephrology, 35, 553-556. https://doi.org/10.1023/B:UROL.0000025649.54702.a6

Submit or recommend next manuscript to SCIRP and we will provide best service for you:

Accepting pre-submission inquiries through Email, Facebook, LinkedIn, Twitter, etc. A wide selection of journals (inclusive of 9 subjects, more than 200 journals)

Providing 24-hour high-quality service

User-friendly online submission system

Fair and swift peer-review system

Efficient typesetting and proofreading procedure

Display of the result of downloads and visits, as well as the number of cited articles

Maximum dissemination of your research work

Submit your manuscript at: http://papersubmission.scirp.org/

Or contact ojneph@scirp.org 